\title{
CANDLE syndrome
}

INSERM

\section{Source}

INSERM. (1999). Orphanet: an online rare disease and orphan drug data base. CANDLE syndrome. ORPHA:325004

Chronic atypical neutrophilic dermatosis with lipodystrophy and elevated temperature (CANDLE) syndrome is a rare autoinflammatory disorder belonging to the proteasome disability syndrome (see this term) group and is characterized by early-onset recurrent fever, swollen violaceous eyelids, prog ressive lipodystrophy, arthralgia, purpuric skin lesions and delayed physical development. 